\title{
Listeria Spinal Cord Abscess - Clinical and MRI Findings
}

\author{
Joseph Y. Chu, Walter Montanera and Robert A. Willinsky
}

\begin{abstract}
Background: Intramedullary spinal cord abscess due to Listeria Monocytogenes is an uncommon condition usually affecting immunocompromised patients. Method: Case study. Results: A 69-year-old man presented with 3 weeks history of subacute paralysis of both lower limbs and the left upper limb. Myelogram and CT scan showed a widened upper cervical cord. CSF revealed lymphocytosis, moderately elevated protein and depressed glucose. A gadolinium-enhanced MRI showed diffuse cervical cord edema with two ring-enhancing lesions at C2-C3. Blood and CSF cultures grew Listeria Monocytogenes. He received IV ampicillin and gentamycin; the latter was discontinued after 1 month due to nephrotoxicity. Serial MRI over the next 3 months showed significant reduction in the size of these abscesses. The patient made a modest improvement in the power of his lower limbs, however he remained bed-ridden. Aside from being a mild, diet-controlled diabetic, there was no evidence of immunosuppression. Conclusion: Listeria spinal cord abscess is a treatable disorder and should be considered in the differential diagnosis in patients with a subacute onset of spinal cord dysfunction.
\end{abstract}

RÉSUMÉ: Abcès à Listeria de la moelle épinière: observations cliniques et RMN. Introduction: L'abcès intramédullaire dû au Listeria monocytogenes est une condition rare qui atteint généralement les patients immunocompromis. Méthode: Étude de cas. Résultats: Un homme âgé de 69 ans s'est présenté avec une histoire de paralysie subaiguë des deux membres inférieurs et du membre supérieur gauche apparue trois semaines auparavant. Le myélogramme et le CT scan ont montré une moelle cervicale haute élargie. Le LCR a montré une lymphocytose, une élévation modérée des protéines et un abaissement du glucose. Une RMN rehaussée au gadolinium a montré un oedème diffus de la moelle cervicale avec deux lésions rehaussantes en anneaux au niveau de C2-C3. Des cultures du sang et du LCR ont révélé la présence de Listeria monocytogenes. Le patient a reçu de l'ampicilline et de la gentamycine IV, cette dernière médication ayant été cessée après un mois à cause de la néphrotoxicité. La RMN sériée sur une période de 3 mois a montré une diminution significative de la taille de ces abcès. La récupération a été minime et le patient est demeuré alité. Ce patient avait un diabète léger contrôlé par la diète. Il n'avait pas d'évidence d'immunosuppression. Conclusions: L'abcès spinal à Listeria est une maladie traitable et devrait être considéré dans le diagnostic différentiel des patients qui ont une dysfonction de la moelle épinière à début subaigu.

Can. J. Neurol. Sci. 1996; 23: 220-223

Listeria Monocytogenes is a gram-positive rod ubiquitous in soil, water and sewage. It was first reported by Nyfeldt in 1929 as a cause of infection in humans. ${ }^{1}$ Since then 186 cases of adult listeriosis have been reported in the English literature by $1980 .^{2}$ Patients with malignancy, ${ }^{3}$ connective tissue disease, ${ }^{4}$ those receiving immunosuppressive drugs, ${ }^{5}$ patients with AIDS, ${ }^{6}$ pregnant women, neonates and the elderly ${ }^{2}$ are particularly prone to develop listeriosis. Although meningitis is the usual form of presentation, rhombencephalitis, ${ }^{7-9,19}$ brain abscess, ${ }^{6,10}$ and spinal cord abscess ${ }^{11 \cdot 13,17,18}$ are increasingly being recognized since the advent of magnetic resonance imaging (MRI). The following is a case report of Listeria spinal cord abscess studied serially with MRI and successfully treated with intravenous ampicillin without surgical intervention.

\section{Case Report}

A 69-year-old right-handed Caucasian man developed subacute onset of paresthesia of his feet and unsteady gait in July 1994. He was otherwise healthy except for mild diet-controlled diabetes mellitus, hypertension, gout and moderate daily alcohol consumption of 2 to $3 \mathrm{oz}$.

Initial examination showed normal mental status and cranial nerves. Motor power was normal in the upper and lower limbs. Deep tendon reflexes were $2+$ and symmetrical in the upper limbs but ankle reflexes

From the Division of Neurology, Queensway General Hospital and The Toronto Hospital (J.Y.C.); Division of Neuroradiology, The Toronto Hospital, University of Toronto (W.M., R.A.W.), Toronto.

RECEIVED OCTOBER 17, 1995. ACCEPTED IN FINAL FORM FEBRUARY 9, 1996

Presented in part at the 30th Canadian Congress of Neurological Sciences Meeting, Victoria, British Columbia, June, 1995.

Reprint requests to: Dr. J.Y. Chu, Queensway General Hospital, 150 Sherway Drive, Etobicoke, Ontario, Canada M9C 1 A5 
were absent. Detailed sensory examinations of the upper limbs were normal; however he had reduction of pain sensation at his toes. The Romberg test was positive and his tandem gait was poor. Laboratory investigations showed WBC $12.1 \times 10^{9} / \mathrm{L}$ with neutrophilia; ESR = 3; random blood sugar was slightly elevated at $9.5 \mathrm{mmol} / \mathrm{L}$. HbAlC was also increased at 0.078 (normal 0.043-0.061). His VDRL was negative, protein electrophoresis was normal, chest X-ray and 5-TU TB skin test were negative. EMG and nerve conduction studies showed a mild sensory-motor peripheral neuropathy of his lower extremities.

Two weeks later, he developed progressive left upper limb and bilateral leg weakness. Examination showed moderate triparesis (MRC power 3/5). His biceps and brachioradialis reflexes were absent bilaterally and the left plantar response was extensor. There was severe loss of vibration and joint-position sense of his feet. CT scan of his brain was normal. A myelogram-CT scan showed an enlarged upper cervical cord with spondylolytic bar at C4-5.

Initial MRI (Figure 1) showed diffuse expansion of the cervical cord from $\mathrm{C} 2$ to $\mathrm{C} 7$ suggestive of significant edema. He received IV dexamethasone (Decadron) for three days with a presumptive diagnosis of post-infectious myelitis. Subsequent gadolinium-enhanced MRI (Figure 2) showed two intramedullary "ring" enhancing lesions. CSF revealed $96 \mathrm{WBC}$ with $90 \%$ lymphocytes, glucose was depressed at $3.9 \mathrm{mmol} / \mathrm{L}$ (blood sugar was $9.5 \mathrm{mmol} / \mathrm{L}$ ), protein was increased to $1.31 \mathrm{~g} / \mathrm{L}$ (nor$\mathrm{mal}<0.45 \mathrm{gm} / \mathrm{L}$ ). The blood and CSF cultures grew Listeria Monocytogenes. His dexamethasone was discontinued and he received $12 \mathrm{gm} / \mathrm{d}$ of IV ampicillin and gentamycin $160 \mathrm{mg} \mathrm{q} 8 \mathrm{~h}$. The latter antibiotic was discontinued after one month due to nephrotoxicity. His HIV test was negative and there was no laboratory evidence of connective tissue disease.

Serial MRIs (Figures 3,4) were obtained over the next 2 months to determine his response to parenteral antibiotic therapy. His overall condition improved slowly over the next few months; however he remained bedridden and was eventually transferred to a chronic rehabilitation unit. Unfortunately, he died suddenly of a myocardial infarction 6 months later and no autopsy was permitted.

\section{Discussion}

Listeria Monocytogenes spinal cord abscess is a rare but potentially treatable cause of subacute spinal cord disorder.

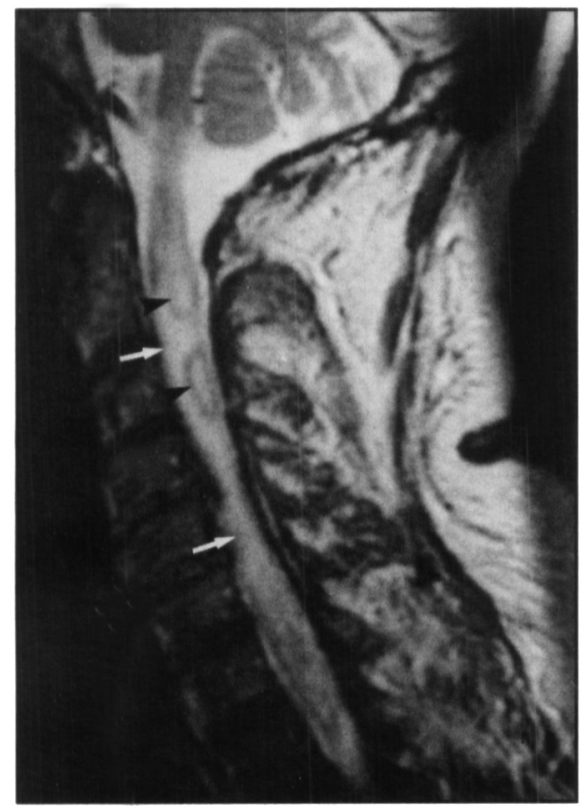

Figure 1: Sagittal T2-weighted MR (TR/TE/excitations, 4000/85/2) shows a diffuse, intramedullary hyperintensity from the lower brainstem to Thl (arrows) with two oval lesions in upper cervical cord (arrow heads).

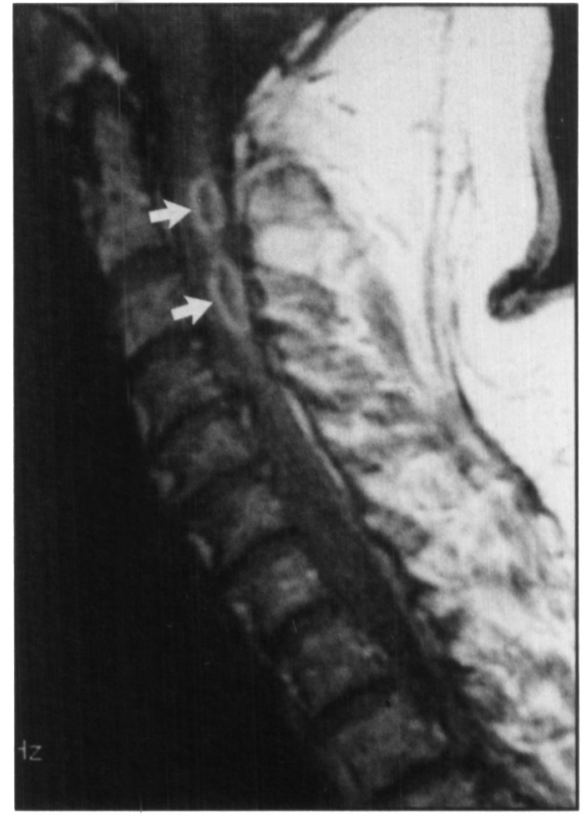

Figure 2: Sagittal gadolinium-enhanced T)-weighted MR (TR/TE/excitations, 616/16/3) shows two intramedullary "ring"enhancing lesions (arrows).

There were five previous cases reported in the English literature ${ }^{11-13.17 .18}$ and the current report is the sixth documented case (Table). The first autopsy case of Listeria spinal cord and brain stem abscess was reported in a healthy 39 -year-old man in Britain (1971). ${ }^{13}$ Kendall et al. ${ }^{11}$ reported the clinical and autopsy

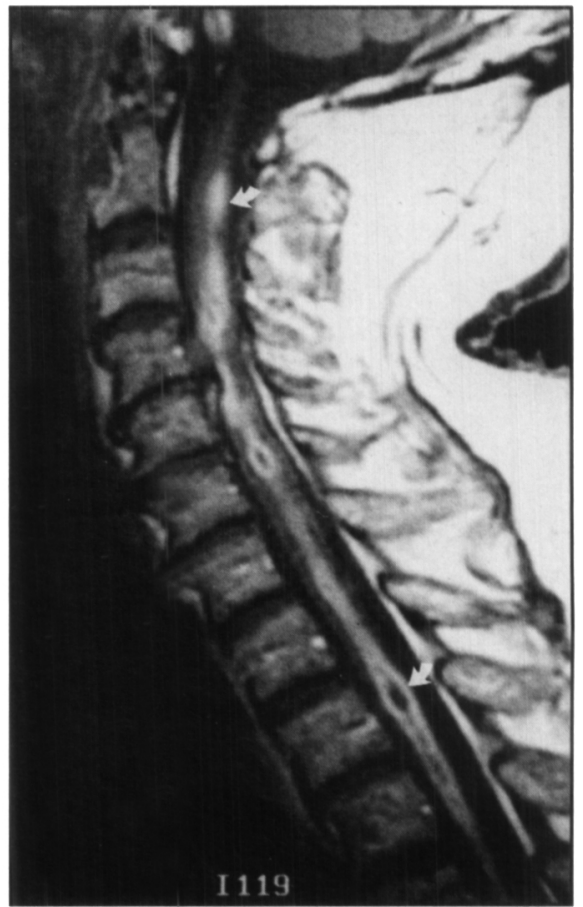

Figure 3: Six weeks after initial $M R$, sagittal gadolinium-enhanced $T I$ weighted MR (TR/TE/excitations, 733/15/2) shows reduction in areas of "ring" enhancement (arrows) in the upper cervical cord but a new lesion is seen at Thl. 
Table: Summary of Listeria Spinal Cord Abscess in English Literature (1970 - 1996).

\begin{tabular}{|c|c|c|c|c|c|c|c|}
\hline Author & Age & Sex & Location & Imaging & Cultures & $\mathbf{R x}$ & Outcome \\
\hline $\begin{array}{l}\text { British Public } \\
\text { Health (1971) }\end{array}$ & 39 & $\mathbf{M}$ & $\begin{array}{l}\text { Upper Cervical Cord } \\
+ \text { Brainstem }\end{array}$ & None & $\begin{array}{c}\text { Abscess of Brainstem } \\
\text { at Necropsy }\end{array}$ & None & Died \\
\hline Morrison (1980) & 32 & $\mathbf{M}$ & Cervical Cord & Myelogram & Open Cord Biopsy (+) & $\begin{array}{l}\text { IV Amp. } \\
\text { \& Chlor.' }\end{array}$ & Ambulatory \\
\hline King (1993) & 50 & $\mathbf{M}$ & Cervical, Brain & Myelo. \& MRI & Blood (+) & Open Biopsy & Died post-op \\
\hline Pfadenhauer (1995) & 73 & M & Thoracic & Myelo. \& MRI & $\operatorname{CSF}(+)$ & $\begin{array}{l}\text { IV Amp. } \\
\text { \& Gent. }\end{array}$ & Paraplegia \\
\hline Chu (1996) & 69 & $\mathbf{M}$ & Cervical, Thoracic & Myelo. \& MRI & Blood, CSF (t) & $\begin{array}{l}\text { IV Amp. } \\
\text { \& Gent. }\end{array}$ & $\begin{array}{l}\text { Triplegia, } \\
\text { died of MI }\end{array}$ \\
\hline
\end{tabular}

'Ampicillin and Chloramphenicol

${ }^{2}$ Ampicillin and Gentamycin

findings of a 68-year-old woman with Th4 to Th8 intramedullary abscess with Listeria monocytogenes meningitis. Her predisposing factor was a history of alcoholism and hepatic cirrhosis. Morrison et al. ${ }^{17}$ described a previously healthy $32-$ year-old man who responded favorably to intravenous antibiotic therapy for a biopsy-proven cervical intramedullary abscess due to Listeria. Since the advent of MRI, two further cases of Listeria spinal cord abscess were reported in the literature by King et al. in $1993^{12}$ and Pfadenhauer et al. in 1995. ${ }^{18}$ The patient in this current case has mild diabetes mellitus which could be a predisposing factor for developing Listeria infections. It is commonly known that diabetics are more susceptible

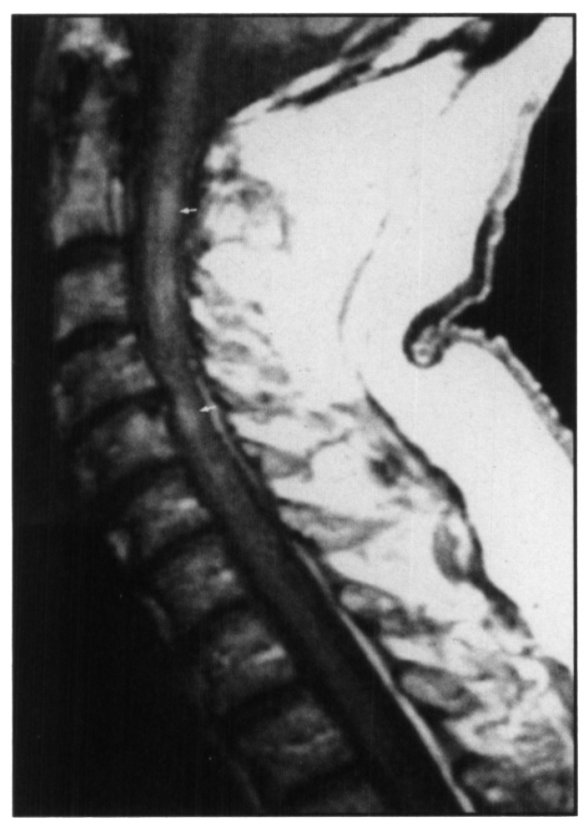

Figure 4: Ten weeks after initial $M R$, sagittal gadolinium-enhanced $T l$-weighted MR (TR/TE/excitations, 633/15/2) shows significant improvement with only minimal patchy enhancement of the cord (small arrows). to develop bacterial and fungal infections due to impaired humoral and cellular immunity. This patient was HIV negative and was not on any immunosuppressive treatments. Although the gastrointestinal tract is considered to be the site of invasion by Listeria, ${ }^{18}$ the fact that it was detected in blood cultures suggests its spread is by hematogenous route.

MRI with gadolinium enhancement is the best neuroimaging technique currently available to accurately document the location and size of intramedullary abscess due to Listeria. Early and adequate intravenous ampicillin ( $12 \mathrm{gm} /$ day) and aminoglycosides is recommended in the treatment due to their synergistic effect. Other antibiotics found to be helpful are rifampin ${ }^{18}$ and chloramphenicol. ${ }^{11,17}$ Nevertheless, despite significant radiological improvement; neurologic function may not fully recover. It has been observed that vasculitis in leptomeningeal and penetrating arteries may result in spinal cord ischemia or even infarction hence explaining the overall unfavorable outcome in neurolisteriosis. ${ }^{19}$ It is therefore important to diagnose Listeria spinal cord abscess early and institute appropriate therapy when patients develop any spinal complications in the course of acute bacterial meningitis.

\section{REFERENCES}

1. Ford PM, Herzberg L, Ford SE. Listeria monocytogenes: Six cases affecting the central nervous system. Q J Med 1968; 146: 281290.

2. Nieman RE, Lorber B. Listeriosis in adults: a changing pattern. Report of eight cases and review of the literature, 1968-1978. Rev Infect Dis 1980; 2: 207-227.

3. Louria DB, Hensle T, Armstrong D, et al. Listeriosis complicating malignant disease - a new association. Ann Intern Med 1967; 67: 261-281.

4. Kraus A, Cabral AR, Sifuentes-Osornio J, et al. Listeriosis in patients with connective tissue diseases. J Rheumatol 1994; 21 : 635-638.

5. Paul ML, Dwyer DE, Chow C, et al. Listeriosis - a review of eighty-four cases. Med J Aust 1994; 160: 489-493.

6. Harris JO, Marquez J, Swerdloff MA, et al. Listeria brain abscess in the acquired immunodeficiency syndrome. Arch Neurol 1989; 46: 250. 
7. Armstrong RW, Fung PC. Brainstem encephalitis (rhombencephalitis) due to listeria monocytogenes: case report and review. Clin Infect Dis 1993; 16: 689-702.

8. Mahony JF, Tambyah JA, Dalton VC, et al. Pontomedullary listeriosis in renal allograft recipient. $\mathrm{Br}$ Med J 1974; 2: 705 .

9. Soo MS, Tien RD, Gray L, et al. Mesenrhombencephalitis: MR findings in nine patients. Am J Neuroradiol 1993; 160: 10891093.

10. Chow AW, Alexander E, Montgomerie JZ, et al. Successful treatment of non-meningitic listerial brain abscess without operation. West J Med 1975; 122: 167-171.

11. Kendall MJ, Clarke SW, Smith WT. Spinal abscess due to listeria monocytogenes in a patient with hepatic cirrhosis. J Pathol 1972; 107: 9-11.

12. King SJ, Jeffree MA. MRI of an abscess of the cervical spinal cord in a case of listeria meningoencephalomyelitis. Neuroradiology 1993; 35: 495- 496
13. Listeriosis. News and notes - epidemiology of listeriosis. Br Med J 1971; 2: 477-478.

14. Buchner LH, Schneierson SS. Clinical and laboratory aspects of listeria monocytogenes infections. Am J Med 1968; 45: 904-921.

15. Cherubin CE, Appleman MD, Heseltine PNR, et at. Epidemiological spectrum and current treatment of listeriosis. Rev Infect Dis 1991; 13: 1108-1114.

16. Kennard C, Howard AJ, Swash M. Infection of the brainstem by listeria monocytogenes. J Neurol Neurosurg Psychiatry 1979; 42: $931-933$

17. Morrison RE, Brown J, Gooding RS, et al. Spinal cord abscess caused by listeria monocytogenes. Arch Neurol 1980; 37: 243-244.

18. Pfadenhauer K, Rossmanith T. Spinal manifestation of neurolisteriosis. J Neurol 1995; 242: 153-156.

19. Uldry PA, Kuntzer T, Bogousslavsky J, et al. Early symptoms and outcome of listeria monocytogenes rhombencephalitis: 14 adult cases. J Neurol 1993; 240: 235-242. 